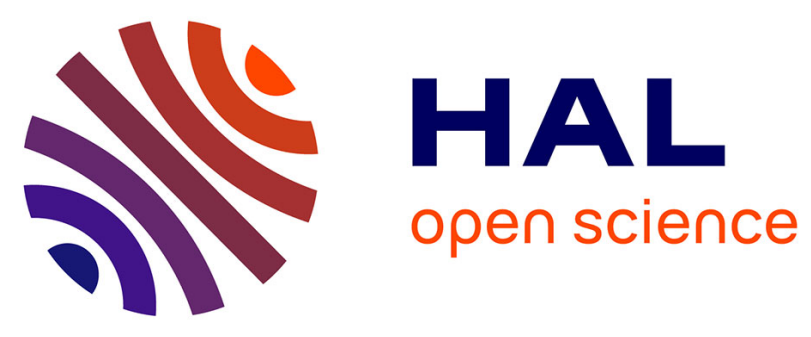

\title{
The relationship between the electrical and mechanical properties of polymer-nanotube nanocomposites and their microstructure
}

Karine Masenelli-Varlot, Laurent Chazeau, Catherine Gauthier, Agnès Bogner-van de Moortele, Jean-Yves Cavaille

\section{To cite this version:}

Karine Masenelli-Varlot, Laurent Chazeau, Catherine Gauthier, Agnès Bogner-van de Moortele, JeanYves Cavaille. The relationship between the electrical and mechanical properties of polymer-nanotube nanocomposites and their microstructure. Composites Science and Technology, 2009, 69 (10), pp.15331539. 10.1016/j.compscitech.2009.01.035 . hal-00431376

\section{HAL Id: hal-00431376 https://hal.science/hal-00431376}

Submitted on 13 Jun 2019

HAL is a multi-disciplinary open access archive for the deposit and dissemination of scientific research documents, whether they are published or not. The documents may come from teaching and research institutions in France or abroad, or from public or private research centers.
L'archive ouverte pluridisciplinaire HAL, est destinée au dépôt et à la diffusion de documents scientifiques de niveau recherche, publiés ou non, émanant des établissements d'enseignement et de recherche français ou étrangers, des laboratoires publics ou privés. 


\title{
The relationship between the electrical and mechanical properties of polymer-nanotube nanocomposites and their microstructure.
}

\author{
K. Masenelli-Varlot, L. Chazeau, C. Gauthier, A. Bogner, J.Y. Cavaillé
}

Université de Lyon, INSA-Lyon, MATEIS, UMR CNRS 5510, F-69621 Villeurbanne cedex, France.

\begin{abstract}
A range of polymer-nanotube nanocomposites were produced using different processing routes. Both polymer-grafted and as-grown nanotubes were used and latex and polystyrene matrices investigated. The microstructures of the nanocomposites were studied, mainly by electron microscopy, in terms of the dispersion state of the nanotubes and the polymernanotube interface. The mechanical and electrical properties of the composites were also measured. The relationship between the microstructures observed and the resulting physical properties are discussed. It is found that composites with apparently similar microstructures can exhibit similar mechanical properties but very different electrical behaviours. Moreover, the nanocomposites produced using polymer-grafted nanotubes exhibit a clear improvement of the stress at large deformation. Thus, from our results, it appears that the mechanical and electrical properties do not necessarily depend on the same microstructural parameters. However it is still a challenge to simultaneously improve both physical properties.
\end{abstract}

Keywords : A. Carbon nanotubes; A. Nanocomposites; B. Electrical properties; B. Mechanical properties; C. Scanning electron microscopy (SEM) 


\section{Introduction}

Since their discovery, carbon nanotubes have attracted intense attention. Researchers have reported Young's moduli for nanotubes that exceed $1 \mathrm{TPa}$ and strengths that are many times higher than the strongest steel at a fraction of the weight ${ }^{1}$. The exceptional mechanical, electrical and thermal properties, size scale, and large aspect ratio of nanotubes make them excellent candidate fillers in multifunctional nanocomposites. Reported potential applications have included electrostatically dissipative materials, advanced materials with combined stiffness, strength and impact resistance for aerospace or sporting goods, composite mirrors, automotive parts that require electrostatic painting and automotive components with enhanced mechanical properties. An abundant amount of literature surrounds the concept of using nanocomposites as a route to realise the extraordinary properties of individual nanotubes on a macroscopic scale. Nevertheless, the expected level of performance is not often reached, i.e. the addition of nanotubes results in a moderate increase of the elastic modulus when compared to the unreinforced polymer ${ }^{2}$. Actually, the nanocomposite properties are related not only to the aspect ratio and intrinsic properties of nanotubes, but also depend on the materials microstructure: the nanotube dispersion state, the nanotube orientation state, and the interactions between nanotubes and polymer chains.

In the field of composite materials, it is often assumed that an increase in interfacial area allows an optimum mechanical stress transfer between the filler and the matrix. For example, the presence of large agglomerates is known to have a dramatic effect on the ultimate properties of the composite and a uniform dispersion of fillers at the nano- or mesoscopic level is aimed for. However, it is also reported that the presence of a certain amount of aggregates can lead to an increase of the elastic properties ${ }^{3}$. These results suggest that an optimum dispersion is needed in order to achieve a good reinforcement in the composites. 
Thus, one of the most significant challenges towards improving the properties of nanocomposites based on carbon nanotubes is to obtain such an optimum dispersion. The main processing methods for producing nanocomposites are melt mixing, solution processing and in-situ polymerization ${ }^{4,5}$ :

1. Melt mixing: Nanotubes are incorporated directly in the polymer melt. This incorporation leads to a high increase of viscosity even at low amounts of filler due to the interactions between the particles (nanotube-nanotube contacts, entanglements) and the high interfacial area (which changes the polymer mobility in the vicinity of the nanotubes). Due to this large viscosity, the air bubbles that are inevitably introduced during the processing are difficult to remove. The problem with high viscosities is worse in the case of long nanotubes as the viscosity increases also with the filler aspect ratio. These processing issues though can be solved generally using high mechanical shear rates and relatively low nanotube loadings. For instance, Thostenson and Chou use a micro-scale twin-screw extruder to achieve dispersion of multi-walled carbon nanotubes in a polystyrene matrix ${ }^{6}$. Sandler et $a l^{7}$ achieved a uniform distribution of nanotubes within an epoxy matrix by repeated stirring at $2000 \mathrm{rpm}$ before and after adding the curing agent. Sonication appears to be one of the most efficient tools to disperse aggregates. But, the practical conditions of this technique (time, power) have to be controlled in order to avoid degradation of the fillers (decrease of their length due to break).

2. Solution processing: A second route consists in using a solvent in which fillers and polymer are first dispersed separately and then mixed together. Some researchers used solution-evaporation methods with high-energy sonication ${ }^{8}$ or surfactant-assisted processing through formation of a colloidal intermediate ${ }^{9}$. The main problem is to obtain a stable suspension of the fillers in the chosen solvent: this stabilization depends on the chemical 
groups on the filler surface. In some cases, the functionalisation of the filler surface can be an efficient way to solve the problem ${ }^{10}$. The covalent chemistry of SWNTs has been reviewed ${ }^{2}$, and this area is actively being investigated.

The stabilization of the filler suspension can also be improved by the use of surfactant molecules, either ionic for electrostatic repulsion, or non ionic for steric stabilisation. To improve the wetting action and the dispersion stability of nanotubes, different surfactants have been proposed. There are ionic surfactants such as sodium dodecyl sulfate (SDS $)^{11}$ which can be used with hydrosoluble polymers as for example polyvinylalcohol (PVA) or polycarbonates. Alternatively non-ionic surfactants have been proposed when organic solvents have to be used like, for instance, when the matrix is an epoxy resin ${ }^{12}$.

As an alternative and more environment-friendly route, water can be used as the dispersion medium. As with other solvents, appropriate grafting or surfactants may aid the dispersion of the nanotubes. Several polymers can be obtained from emulsion polymerisation, such as latex, to give nanosized particles in an aqueous suspension. The latex route has been extensively used by Cavaillé and coworkers ${ }^{11,12,13}$ in order to process cellulose whiskers composites. Carbon nanotubes based nanocomposites can be prepared by mixing a latex and an aqueous suspension of carbon nanotubes ${ }^{14,15}$.

3. in situ polymerisation: Another way is to disperse the fillers in the monomer or prepolymer and then polymerize. In this case, the issue is to control the polymerisation or the curing process which might be modified by the filler. Park and al. synthesized SWNT/polyimide nanocomposites by in situ polymerisation under sonication ${ }^{16}$. Polystyrene nanocomposites with functionalised single-walled carbon nanotubes (SWNTs) were prepared by in situ 
generation and reaction of organic diazonium compounds ${ }^{17}$. Polystyrene $(P S)$ can also be grafted onto the nanotubes using living radical polymerisation, such as Nitroxide Mediated Radical Polymerisation ${ }^{18}$ (NMRP) or Atomic Transfer Radical Polymerisation (ATRP), which is used in the present paper $^{19}$. Such techniques can also be used to obtain functionalised carbon nanotubes that can be incorporated in the polymer matrix by melting or solvent route. For instance, in the case of polyimide-carbon nanotube composite films prepared via wetcasting, an amino-terminated polyimide was synthesised and used in the functionalisation of carbon nanotubes ${ }^{20}$. This, however, modifies the surface chemistry and therefore influences the filler-matrix interface.

It is interesting to note that not only does the surface treatment of nanotubes, implying a surface functionalisation by grafting polymer chains or the use of surfactants, have an interest for the sample processing, but also effects the role of the interfacial adhesion for electrical or for load transfer governing the interfacial shear stress. Note also that, in addition to uniform dispersion of nanotubes within the matrix, some reported works ${ }^{6}$ aim to process model systems with controlled structures and alignments so that the axial load-carrying efficiency of the nanotube can be used ${ }^{21}$.

In order to advance the fundamental understanding of the nanoscale reinforcement mechanisms, this paper discusses the relationships between processing route, microstructure characterization, thermomechanical and electrical behaviour. We have chosen the route of solution processing and in situ polymerisation to produce these samples, enabling us to obtain a range of different microstructures. Based upon these samples, we will be show that composites with apparently similar microstructures can exhibit similar mechanical properties 
but very different electrical behaviours. This result will help us identifying the microstructural parameters that significantly play a role on the macroscopic properties.

\section{Experimental}

\section{Processing of the nanocomposites}

\begin{tabular}{|c|c|c|c|}
\hline Acronym & Matrix & Nanotubes & Processing conditions \\
\hline LAT1 & $\begin{array}{c}\mathrm{P}(\mathrm{S}-\mathrm{aBu}) \text { latex } \\
35 \text { wt } \% \text { styrene and } \\
65 \text { wt } \% \text { butyl } \\
\text { acrylate }\end{array}$ & $\begin{array}{l}\text { MWNTs prepared by catalytic } \\
\text { decomposition of acetylene at } \\
720^{\circ} \mathrm{C} \text { on a supported } \\
\text { cobalt/iron catalyst }^{22}\end{array}$ & $\begin{array}{l}\text { Dispersion of the MWNTs in water } \\
\text { with } 0,9 \mathrm{~g} / \mathrm{l} \text { sodium dodecylbenzene } \\
\text { sulfonate (SDBS) } \\
\text { - Mixing of the latex solution and the } \\
\text { MWNT solution to obtain composites } \\
\text { with } 3 \mathrm{wt} \% \text { MWNTs } \\
\text { - Film formation by water evaporation } \\
\text { (at } 35^{\circ} \mathrm{C} \text { under vacuum for } 5 \text { days) }\end{array}$ \\
\hline LAT2 & $\begin{array}{c}\mathrm{P}(\mathrm{S}-\mathrm{aBu}) \text { latex } \\
35 \mathrm{wt} \% \text { styrene and } \\
65 \text { wt } \% \text { butyl } \\
\text { acrylate }\end{array}$ & $\begin{array}{l}\text { MWNTs prepared by catalytic } \\
\text { decomposition of acetylene at } \\
720^{\circ} \mathrm{C} \text { on a supported } \\
\text { cobalt/iron catalyst }{ }^{22}\end{array}$ & $\begin{array}{l}\text { Dispersion of the MWNTs in water } \\
\text { with 0,9g/l sodium dodecylbenzene } \\
\text { sulfonate (SDBS) } \\
\text { - Mixing of the latex solution and the } \\
\text { MWNT solution } \\
\text { - } \quad \text { Film formation by freeze-drying and } \\
\text { hot-pressing (at } 100^{\circ} \mathrm{C} \text { for } 5 \text { min under } \\
1 \mathrm{MPa} \text { ) }\end{array}$ \\
\hline SOL1 & PS & $\begin{array}{l}\text { CNx produced using a CVD } \\
\text { process } \\
\text { involving solutions containing } \\
2.5 \mathrm{wt} \% \text { of ferrocene } \\
\text { in benzylamine. The solution } \\
\text { was atomized using an abrupt } \\
\text { Ar pressure difference } \\
\text { A3 }\end{array}$ & $\begin{array}{c}\text { - Mixing of PS and CNx in toluene } \\
\text { - } \quad \text { Film formation by toluene evaporation } \\
\text { - } \quad \text { Hot-pressing (at } 150^{\circ} \mathrm{C} \text { for } 5 \text { minutes } \\
\text { under } 1 \mathrm{MPa} \text { ) }\end{array}$ \\
\hline SOL2 & - & PS-grafted CNx & $\begin{array}{c}\text { Grafting of polystyrene by ATRP without } \\
\text { any hot-pressing }\end{array}$ \\
\hline SOL3 & PS & PS-grafted $\mathrm{CNx}$ & $\begin{array}{l}\text { - Mixing of PS and PS-g-CNx in } \\
\text { toluene } \\
\text { - } \quad \text { Film formation by toluene evaporation } \\
\text { - } \quad \text { Hot-pressing (at } 150^{\circ} \mathrm{C} \text { for } 5 \text { minutes } \\
\text { under } 1 \mathrm{MPa} \text { ) }\end{array}$ \\
\hline
\end{tabular}

Table 1: nomenclature and description of the studied polymer/nanotube nanocomposites.

Table 1 summarises the processing stages used to produce each of the samples used in this study. All these samples were formed by solution processing with either polystyrene or latex being used as the matrix. The first two samples (LAT1 and LAT2) were produced by dispersing nanotubes using a SDBS surfactant and then mixing the dispersion with a ploy(styrene-butyl acrylate ) latex, which synthesis is detailed elsewhere ${ }^{15}$. Films were then produced by water evaporation under raised temperatures (LAT1) or freeze-drying followed 
by hot pressing (LAT2). The polystyrene matrix samples (with Resirene HH-104 industrial product) were produced using nitrogen doped nanotubes $(\mathrm{CNx})$ as the filler. SOL1 sample was been prepared by using the as-produced nanotubes whereas SOL2 and SOL3 used nanotubes which had polystyrene grafted onto them using ATRP, as described in detail in reference 19 .

\section{Characterisation conditions}

Controlled-pressure Scanning Electron Microscopy (CP-SEM) was used to probe the dispersion of the nanotubes in solution and to observe the surfaces of LAT1 and LAT2. A droplet of the aqueous solution of nanotubes was deposited on a 400-mesh copper grid covered with a holey carbon film. The grid was then placed on a wet-STEM specimen holder and observed on a FEI XL-30 ESEM equipped with a field emission gun, in wet-STEM mode ${ }^{24}$. The accelerating voltage was set to $30 \mathrm{kV}$, the temperature between 2 and $3{ }^{\circ} \mathrm{C}$ and the partial pressure of water was ranging between 5 and 6 Torr. Unfortunately by this technique, it is not possible to know the exact filler content, since an unknown amount of water is evaporated to obtain in situ a sample thin enough to view directly in the microscope. The images were recorded with a high angle annular dark field detector placed under the grid. The surfaces of LAT1 and LAT2 were also observed with that microscope, without any conductive coating, under vacuum. The accelerating voltage was set to $20 \mathrm{kV}$ and the images were recorded with the Everhart-Thornley detector. The fractured surfaces of SOL1 and SOL3 were observed under the same conditions, except for the accelerating voltage, set to $800 \mathrm{~V}$ in order to highlight the polymer-nanotube interface. For each specimen, several images were acquired at very different positions to check that they were representative of the overall microstructure. 
For the electron tomography experiments, the LAT1 sample was cut on a Ultramicrotome Reichert S, with a $45^{\circ}$ diamond knife. The temperature was set to $-20^{\circ} \mathrm{C}$ and the knife speed to $1 \mathrm{~mm} / \mathrm{s}$. The thin sections were then mounted on 300-mesh copper grids. Electron tomography was performed at the FEI application centre (Eindhoven) on a Tecnai $\mathrm{G}^{2}$ Sphera ( $\mathrm{LaB}_{6}$ filament, $200 \mathrm{kV}$ ). The image series were acquired with tilts ranging from $-70^{\circ}$ to $70^{\circ}$. The volume was reconstructed via Inspect3D.

The glass transition temperatures of SOL1, SOL2 and SOL3 were determined by Differential Scanning Calorimetry using a temperature ramp rate of $1 \mathrm{~K} / \mathrm{min}$., with a nitrogen gas flow of $40 \mathrm{~mL} / \mathrm{min}$.

For samples LAT1 and LAT2, in situ electrical conductivity measurements were carried out during a tensile test, as previously for other conductive nanocomposites ${ }^{25}$. Parallelepipedic samples (around $5 \times 15 \times 0.7 \mathrm{~mm}^{3}$ ) were coated at their ends with a silver paint to ensure a good electrical contact. Electrodes and samples were carefully isolated from the tensile machine. Longitudinal AC complex electrical conductivity measurements were performed at ambient temperature for several frequencies ranging from $10 \mathrm{mHz}$ to $1 \mathrm{MHz}$ using a Solartron 1226 bridge with a low applied field of about $1 \mathrm{~V} / \mathrm{cm}^{26}$. Tensile tests were performed on a MTS device (MTS 1/ME) with an initial strain rate of $2.710^{-3} \mathrm{~s}^{-1}$.

For samples SOL1, SOL2 and SOL3 compression tests were performed using an INSTRON standard mechanical testing machine equipped with parallel plateaus. The samples we used consisted of cylinders with a diameter of $4.5 \mathrm{~mm}$ and a length of $8 \mathrm{~mm}$. The diameter/length ratio used eliminated undesirable deformations such as buckling. Furthermore, in order to restrain barreling effect, the contact surfaces of the sample were polished and lubricated with 
molybdenum disulphide $\left(\mathrm{MoS}_{2}\right)$. To ensure an accurate measurement of the strain, a video device was used to follow the deformation of the samples, using marks previously etched on their surfaces.

\section{Microstructural characterisation}

It is well known that several microstructural parameters may affect the macroscopic properties of filled polymer nanocomposites. When nanotubes are used as fillers, these parameters are their dispersion state, the nanotube-nanotube contacts (or entanglements) and the polymer-nanotube interfacial adhesion strength.

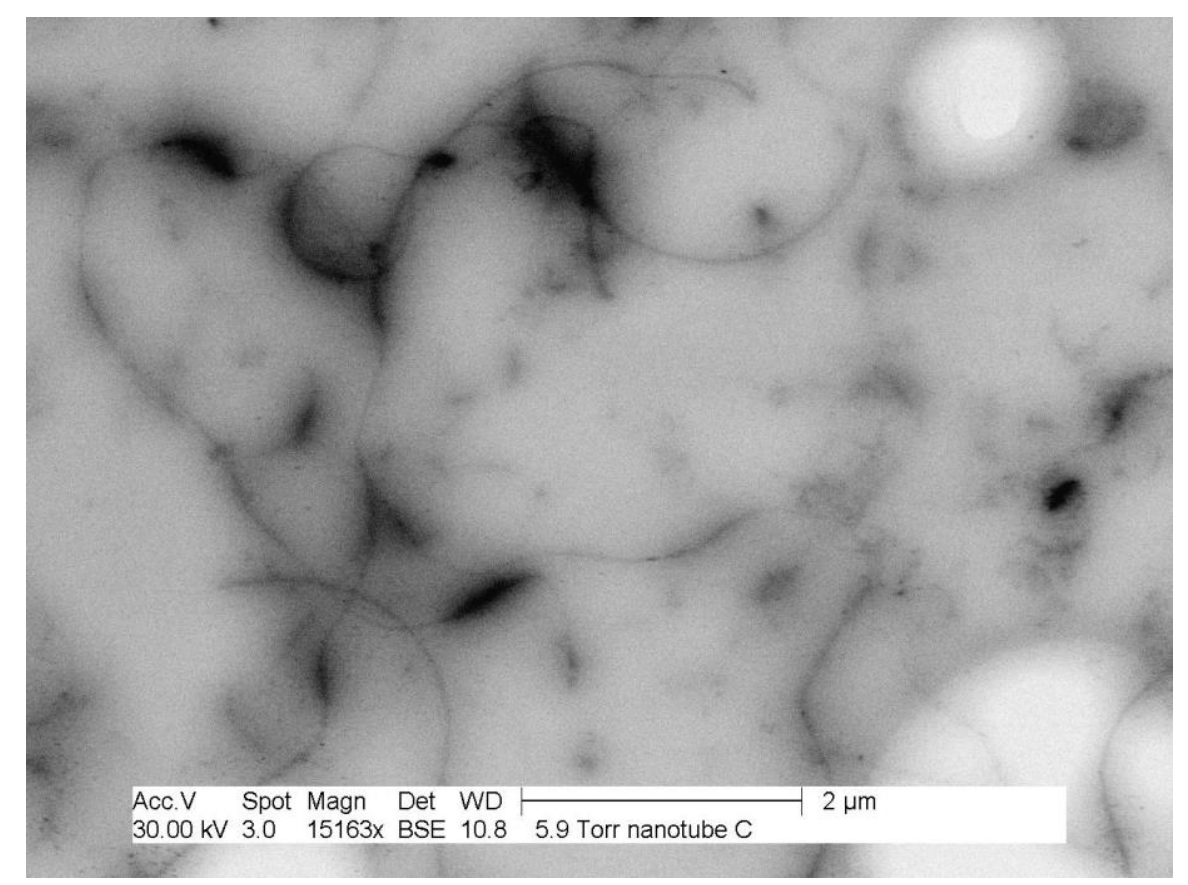

Figure 1 : Aqueous suspension of the MWNTs used for the elaboration of LAT1 and LAT2. Observation in CP-SEM, in the wet-STEM mode. The nanotubes appear in black.

\section{Nanotube dispersion state}

The nanotube dispersion state in a polymer matrix is a major issue, especially if the nanotubes are in bundles (SWNTs) or aligned on a substrate (MWNTs) after synthesis. One way to check their dispersion in a solvent, before incorporating them to a matrix, is to observe the nanotube dispersion by CP-SEM. In Figure 1 is displayed an image of the aqueous suspension 
of the MWNTs used for the elaboration of LAT1 and LAT2. The image was acquired in transmission and the nanotubes appear in black. Even though some parts of the nanotubes are out of focus and appear as diffuse dark regions in the image, it can be concluded from the image that the nanotubes are well separated from each other.
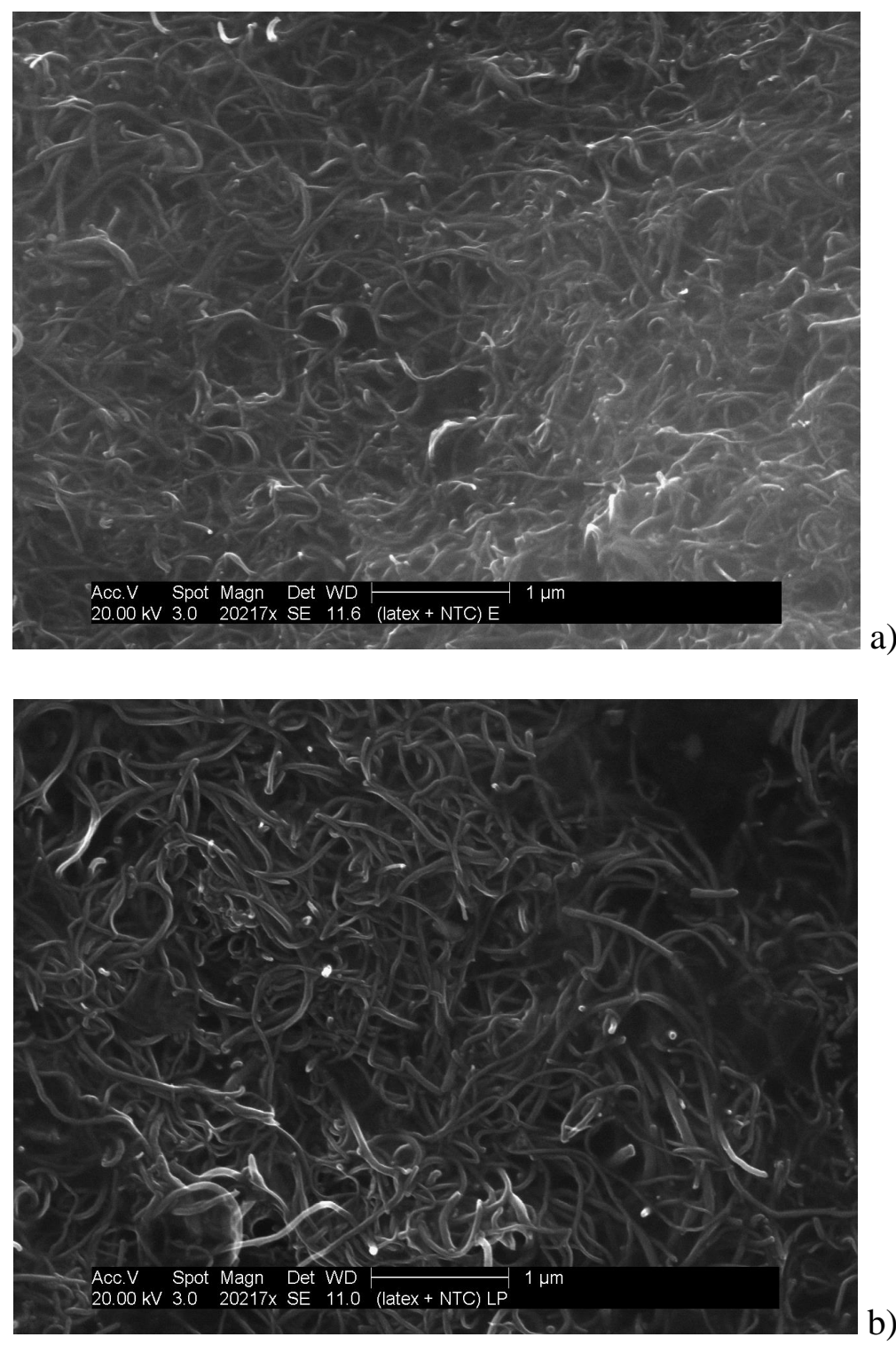

Figure 2 : surfaces of a) LAT1 (3 vol\% MWNTs), b) LAT2 (3 vol\% MWNTs) observed by CP-SEM.

After elaboration, the surfaces of LAT1 and LAT2 were observed by CP-SEM, see Figure 2. The surface of LAT1 is slightly uneven, with few holes. The surface of LAT2 seems to be smooth, although asperities can occur after hot-pressing. Moreover, the good contrast between 
the conductive nanotubes and the insulating matrix gives volume information: the nanotubes below the surface can be detected. From the images, it can be concluded that the nanotube dispersion state is excellent, with no nanotube aggregation. No difference in the nanotube dispersion state can be detected between LAT1 and LAT2.

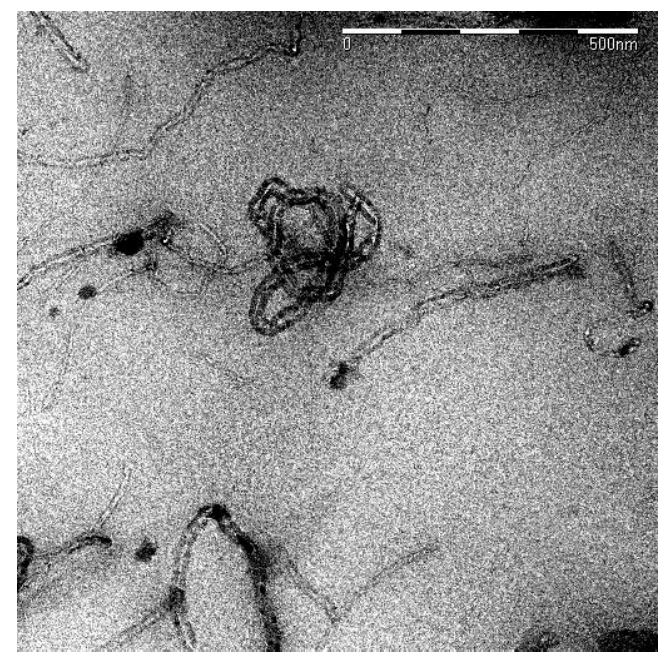

a)

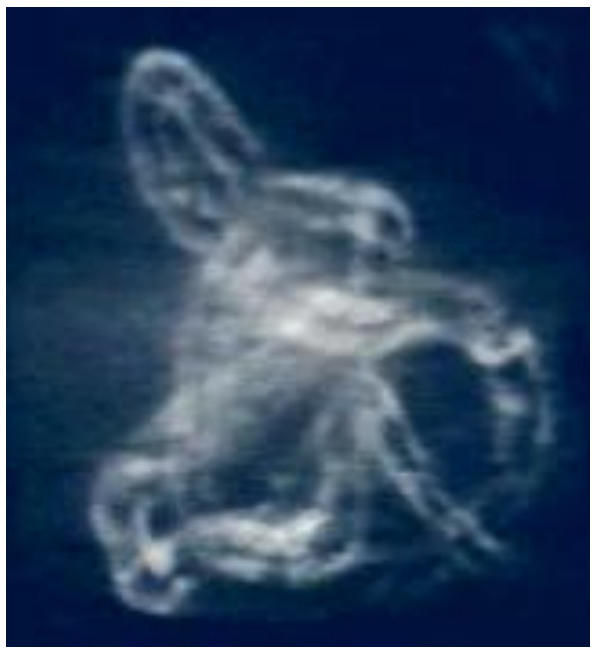

b)

Figure 3 : a) TEM bright field image of LAT1 (scale bar $500 \mathrm{~nm}$ ) and b) electron tomography reconstructed volume of the nanotube in the middle of the TEM image.

\section{Nanotube-nanotube contacts / entanglements}

The characterisation of the contacts / entanglements is still difficult. Indeed, a threedimensional view of the nanotubes in the nanocomposites has to be obtained at high spatial resolution. Electron tomography has been shown to be an efficient technique to image the dispersion state of carbon nanotubes in a polymer matrix in three dimensions ${ }^{27}$. An example of electron tomography performed on LAT1 is displayed in Figure 3. Unfortunately, due to the limited size of the reconstructed volume, it is not possible to visualize a large number of nanotube-nanotube contacts / entanglements. As a consequence, no statistical information regarding the contacts/entanglements is obtained and it will be further considered that LAT1 and LAT2 exhibit similar microstructures. 

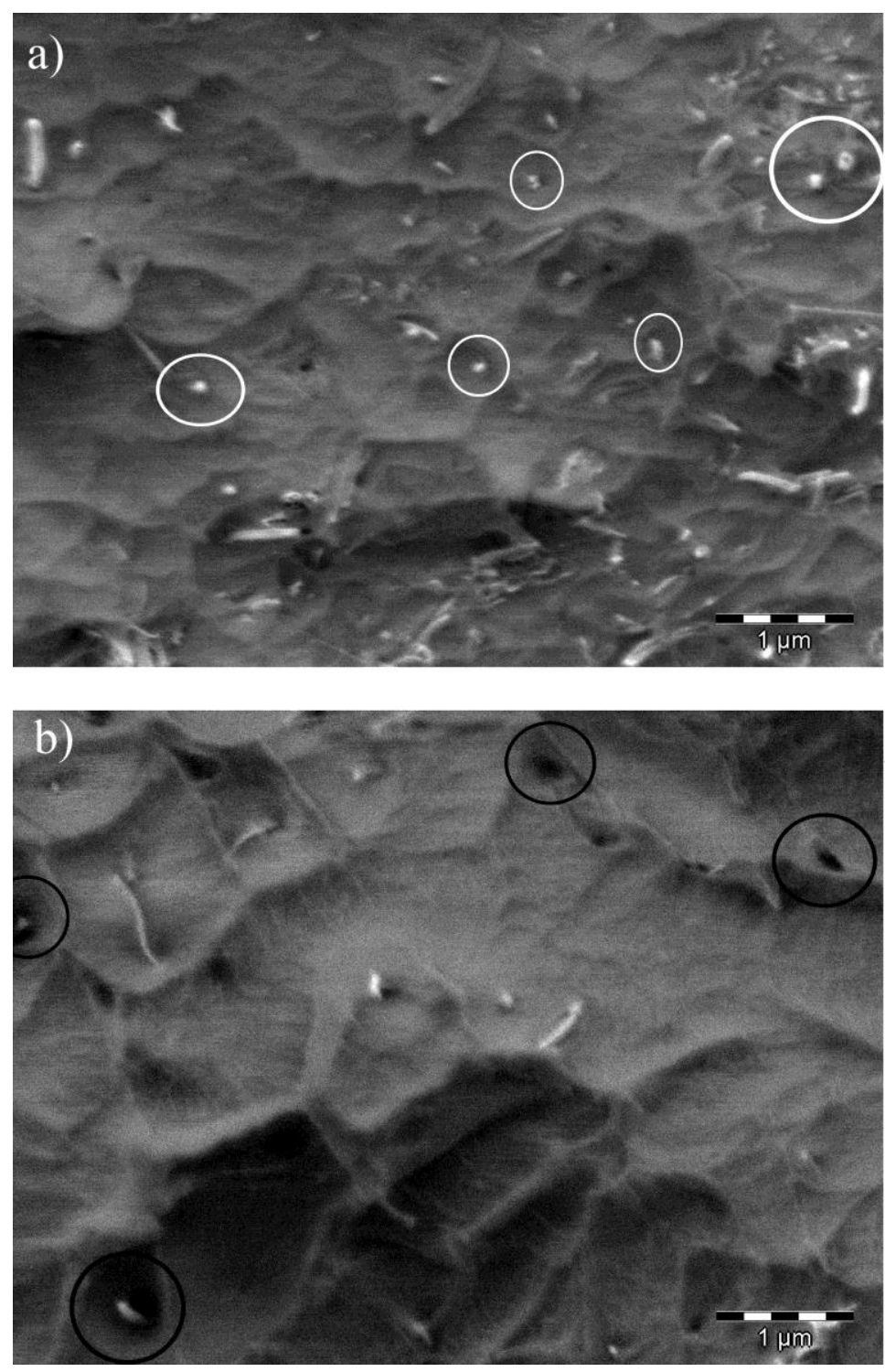

Figure 4: SEM micrographs of the $\mathrm{CN}_{\mathrm{x}}$ MWNTs / PS nanocomposites after breaking at ambient temperature; a) SOL3 (2.5 vol.\% PS-g-CNx) with white circles indicating cut tubes; b) SOL1 (2.5 vol.\% $\mathrm{CN}_{\mathrm{x}}$ ), the black circles indicate holes or pulled out tubes.

\section{Interfacial Adhesion Strength}

The interfacial adhesion strength can be modified by nanotube functionalisation. In the present study, the polystyrene was grafted onto the surface of nitrogen-doped carbon multiwalled nanotubes (CNx), by Atom Transfer Radical Polymerisation (ATRP). The improvement of the interfacial adhesion strength is expected to occur through the entanglements of the matrix chains and the grafted chains, which are covalently linked to the nanotubes. 
SEM micrographs of SOL1 and SOL3 after breaking at ambient temperature are displayed in Figure 4a and Figure 4b, respectively. Interestingly, the portions of nanotubes which exit from the fractured surface appear very bright since secondary electrons can easily escape from those small conductive tips. The fracture surface of SOL1 thus reveals pulled-out tubes, which indicates that the fracture propagated at the matrix/nanotube interface (poor interfacial adhesion strength). On the contrary, cut nanotubes are most of the time detected on the fracture surface of SOL3. This is indicative of an increase of the interfacial adhesion strength with the presence of the grafted polystyrene layer.

Note that the presence of a grafted polymer layer is likely to induce other microstructural changes and thus different macroscopic properties, such as the glass transition temperature of the material and the nanotube dispersion state. As far as the nanotube dispersion state is concerned, with the chosen processing route, it depends on the nanotube-nanotube interactions in solvent and thus on the solution stability. It was previously observed on very similar systems that grafting polymer drastically improved the stability, the solution becoming stable over weeks ${ }^{28}$. The SEM observations at lower magnification of SOL1 and SOL3 (not displayed) seemed to confirm this result.

The glass transition temperatures of SOL1, SOL2 and SOL3 are displayed in Figure 5. Pure PS exhibits a glass transition at $99^{\circ} \mathrm{C}(372 \mathrm{~K})$, in agreement with values reported in the literature $^{29}$. SOL1, with 2.5 vol\% CNx does not exhibit any significant change in the matrix glass transition found at $98^{\circ} \mathrm{C}(371 \mathrm{~K})$. On the contrary, SOL3 with $2.5 \%$ vol. of PS-g-CNX present a glass transition shifted down to $92^{\circ} \mathrm{C}(365 \mathrm{~K})$ and laying from $80^{\circ} \mathrm{C}$ to $99^{\circ} \mathrm{C}(353 \mathrm{~K}$ to $372 \mathrm{~K})$. This can be attributed to the presence of the grafted layer, since SOL2 also exhibits a lower glass transition temperature $\left(83.5^{\circ} \mathrm{C}\right.$ or $\left.356.5 \mathrm{~K}\right)$. It is well known ${ }^{29}$ that the 
polystyrene glass transition temperature Tg is almost constant for molecular weight (Mn) over $10^{5}$. Below this value, the glass transition temperature starts to decrease, following an empirical relation such as: $T g=T g_{\infty}-\frac{k}{\overline{M w}}$, where $\mathrm{k}$ is a constant $\left(\approx 1.710^{5}\right.$ for PS $)$ and $\mathrm{Tg}_{\infty}$ refers as to Tg for very large $\overline{M w}$. It means that the low glass transition temperature observed for SOL2 results from the low grafted polystyrene molecular weight. From the previous equation, it is concluded that the molecular weight of the polystyrene grafted on the external layer of the $\mathrm{CN}_{\mathrm{X}}$ is about $10^{4} \mathrm{~g} \cdot \mathrm{mol}^{-1}$. Moreover, Matyjaszewski ${ }^{30}$ showed that ATRP grown polystyrene generally have low molecular weights, which is consistent with the value found for SOL2. One possibility to increase the molecular weight of the grafted polystyrene chains may be to increase the polymerisation time, or to use another grafting procedure ${ }^{31,32,33}$.

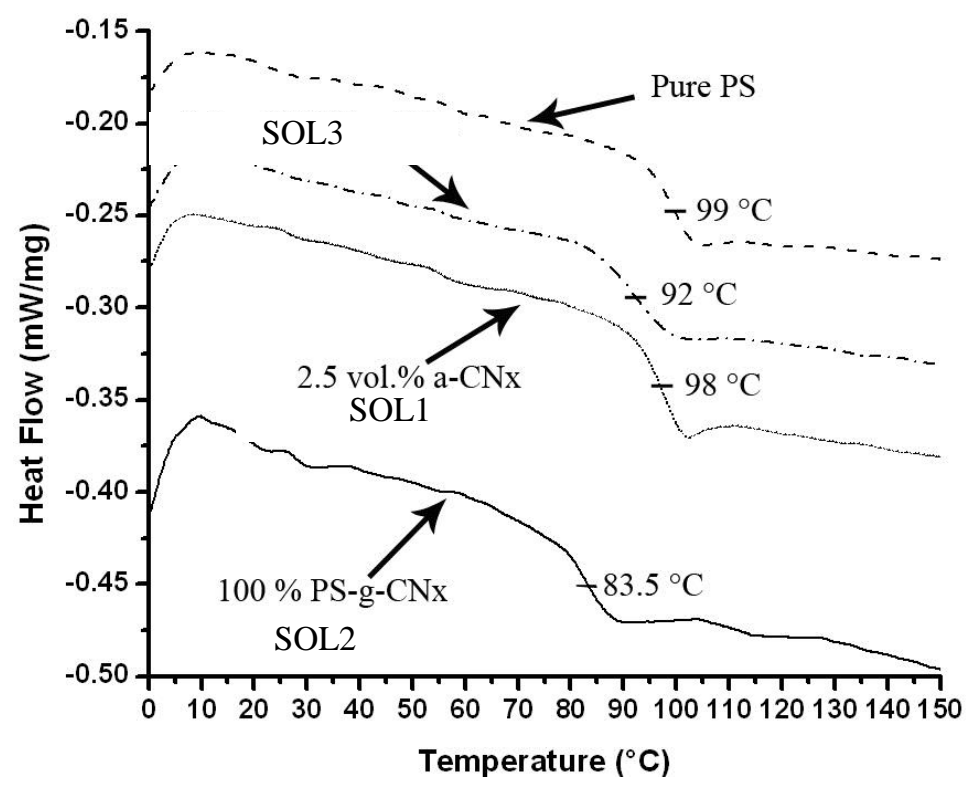

Figure 5 : Glass transition of the PS matrix; SOL1 (2.5 vol.\% CNx), SOL2 (pure PS-gCNx, no added matrix) and SOL3 ( 2.5 vol.\% PS-g-CNx). The weight involved in the heat flow scale refers to pure polymer (nanotubes weight has been deducted)

As a conclusion, it will be considered from the microstructural characterisation that LAT1 and LAT2 exhibit similar microstructures. On the contrary, the microstructure of SOL1, SOL2 
and SOL3 differ in terms of glass transition temperature, nanotube dispersion state and interfacial adhesion strength.

\section{Mechanical and electrical properties}

The fact that carbon nanotubes are electrically conductive makes them very specific compared to most of fillers used for polymer based nanocomposites. In the present work, in situ electrical measurements during mechanical testing were performed. The idea is to study whether the process plays a role on the macroscopic properties, although no significant difference in the microstructure was found (samples LAT1 and LAT2). This is performed by using alternative current over a wide frequency range. As discussed elsewhere ${ }^{34}$, it is a way to discriminate situations where fillers form a continuous network, i.e. where fillers are in contact, or alternatively, if they are separated by a short distance. In the first case, the electrical conductivity does not depend on the frequency, while in the second case, it does, following the capacitor admittance behaviour versus frequency.
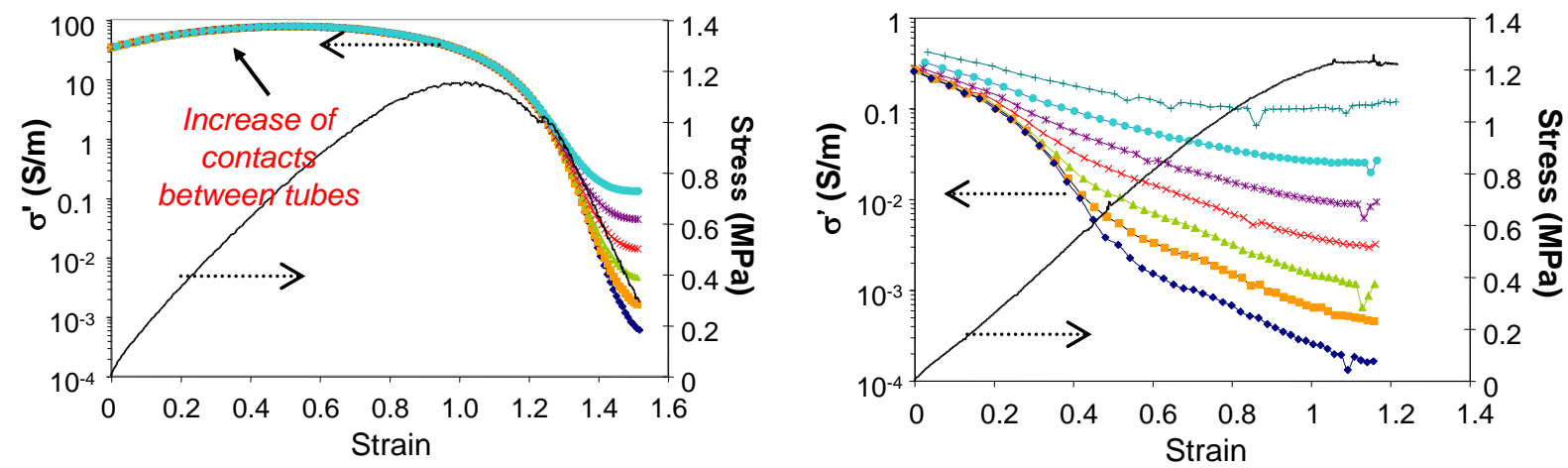

Figure 6: in situ electrical conductivity measurements performed on: left, LAT1, right LAT2. Each curve corresponds to frequency increasing (bottom) from $1 \mathrm{kHz}$ to $1 \mathrm{MHz}$ (top).

The two specimens LAT1 and LAT2 were submitted to a tensile test and their in situ electrical behaviour versus strain exhibited in Figure 6 show very different features. The stress-strain curves are also plotted. First of all, the tensile curves reflect the viscous behaviour of the matrix (the tensile tests are performed at ambient temperature, which is far 
above the glass transition temperature of the matrix). Nevertheless, the composites still display an elastic response, attributed to the presence of a nanotube network. It is noteworthy that the tensile curves relative to LAT1 and LAT2 are similar, as expected since both samples exhibit similar microstructures. However, for LAT1, it is clear that the electrical conductivity is (i) independent of the frequency up to about $\varepsilon=1.3$, (ii) almost constant, even with a slight increase at the beginning of the test, and finally decreases rapidly with a clear splitting of the curves, each of them corresponding to a different frequency. The higher the frequency, the higher the conductivity, which is the signature of a capacitance behaviour. For LAT2, the situation is drastically different. First of all the conductivity at zero strain is about a hundred times lower than for LAT1. The higher conductivity at zero strain of LAT1 compared to LAT2 is most probably due to the formation of percolating pathways during the production of the LAT1 due to its slower solvent evaporation. In the case of LAT2, freeze-drying is a quick process a more limited number of percolating pathways were formed, which lowers the electrical conductivity. Moreover for LAT2, from the beginning of the stress-strain curve, the conductivity is frequency dependent, and this effect increases with the sample elongation. The different electrical behaviour has to be related to a difference in their microstructures, which could not be detected during the microstructural characterisation: the only difference between LAT1 and LAT2 is again their production steps. LAT1 results of the slow water evaporation of a diluted latex and CNT colloidal suspension, which takes several days, while LAT2 has been obtained by freeze-drying of the same colloidal suspension. In the diluted state, CNT have a low probability to be entangled, but at increasing concentration (during evaporation) this probability increases, allowed by Brownian motions. On the contrary, freeze-drying avoids the formation of entanglements, and the hot pressing step has no reason to enhance this formation. Thus if we assume that LAT1 contains entangled CNT, stretching it will first result to a stronger contact at the entanglement contacts, which explains (i) the slight but 
reproducible conductivity increase and (ii) its resistive behaviour (frequency independence). However, for higher strains, the nanotubes start to disentangle, which leads to the contact loss and switches the electrical behaviour from resistive to capacitive (frequency dependence). For LAT2, contacts provided by the hot-pressing step disappear as soon as the stretching starts.

One can ask why CNT entanglements do not improve the mechanical behaviour as seen from the tensile tests. In fact, the adhesion between CNT and the matrix is very weak, as well as between CNT-CNT, so almost no reinforcing effect comes from CNT entanglements. To obtain more efficiency on the CNT mechanical reinforcing effect, this adhesion needs to be enhanced by, for instance, macromolecular grafting.

As far as samples SOL1 and SOL3 are concerned, it was concluded from the microstructural characterization that they differ in terms of nanotube dispersion state and interfacial adhesion strength. The electrical properties of similar materials were studied elsewhere ${ }^{35}$. As expected the grafting of polymer onto the nanotubes results in a drastic decrease of the electrical conductivity, since the nanotube are covered by a uniform insulating layer. Compression tests were used to study the difference in mechanical properties between both materials. Figure 7 displays the compression curves of several materials, including the matrix (PS), SOL1 (labeled on the top of Figure 7 as " 2.5 vol.\% a-CNx") and SOL3 (labeled on the bottom of Figure 7 as " 2.5 vol.\% PS-g-CNx"). It is noteworthy that the addition of nanotubes increases the yield stress in all cases. For SOL1 the yield stress increases by $12 \%$, whereas it increases by $20 \%$ for SOL3. At higher strain, i.e. in the steady state region $(\varepsilon>15 \%)$, the behaviours of SOL1 and SOL3 are also different. For SOL1, the stress appears to be constant, whereas, for SOL3, a hardening phenomenon appears very clearly. These results can be attributed to an increase of the load transfer, due to the higher interfacial adhesion strength in SOL3. 

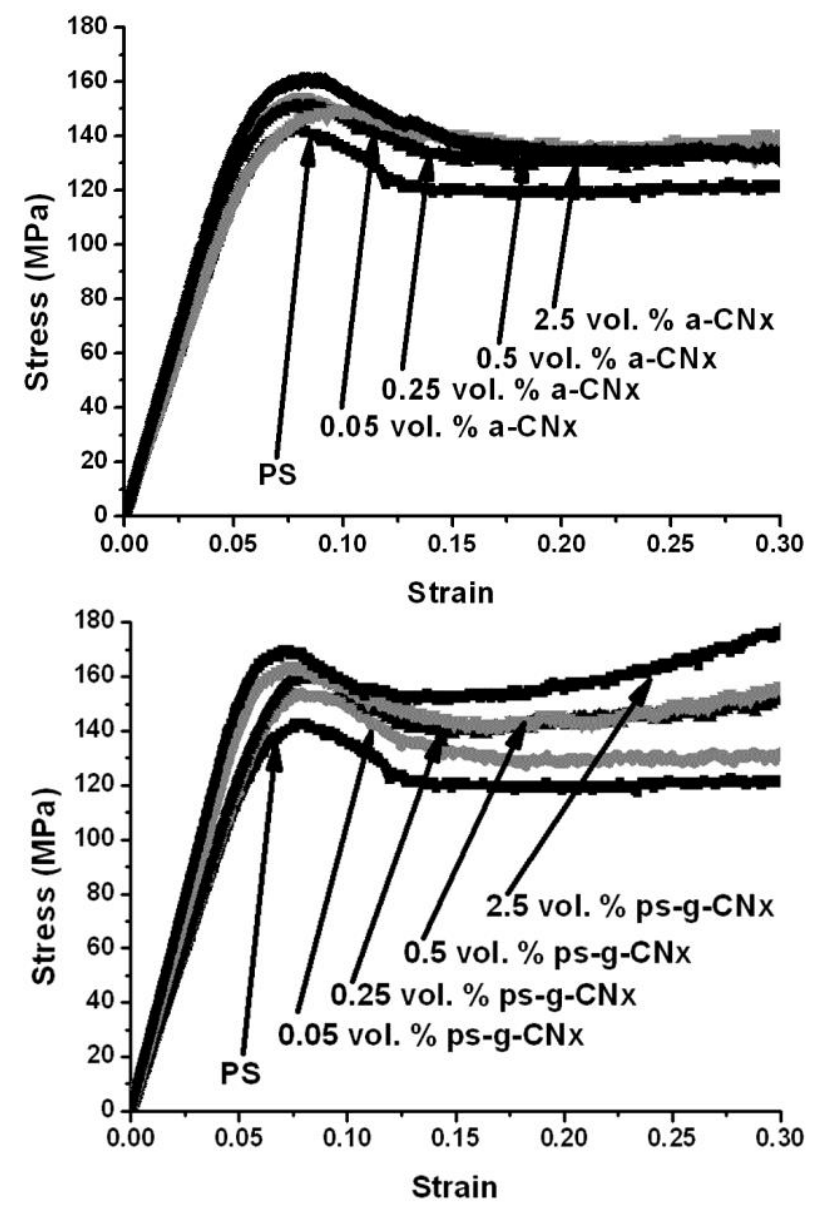

Figure 7: Compression tests for composites with: top) as received $\mathrm{CNx}$; bottom)

\section{PS-grafted-CNx}

The hardening is a complex phenomenon that is still being investigated. In pure polymers, it is often observed and has been discussed many times by many authors ${ }^{36,37,38}$. In the case of composites or nanocomposites, it has been pointed out that the appearance of damage at the beginning of the steady state may compensate the hardening which is expected even stronger than for the matrix alone ${ }^{39}$. It is probably the case of SOL1, for which the matrix/nanotube interface is broken and consequently the matrix/nanotube load transfer is not efficient anymore (damage effect). It means that in the case of SOL1, the activation of pull out phenomenon appears at the matrix yield stress. On the contrary, it seems that the polymer grafting in SOL3 permits to partially avoid the interface breaking by limiting the pull out phenomenon. 


\section{Conclusions}

Five different polymer/nanotube nanocomposites were elaborated to study the relationships between the processing route and the nanocomposite microstructure, mechanical and electrical properties. By adjusting the processing route or the grafting of the nanotubes, different states of dispersion, of entanglement and interface were obtained. It has been shown that with apparently the same levels of dispersion (as evidenced by electron microscopy) and the same mechanical properties, nanotube composites can exhibit very different electrical properties. The electrical properties are indeed much more sensitive to the nanotube-nanotube contacts made through their entanglements. The apparent contradiction between electrical and mechanical measurements comes from the weak nanotube-polymer interaction which inhibits the reinforcing role of the entanglements at large deformation.

Thus, given the importance of the interfacial adhesion strength, polymer-grafted nanotubes were used as fillers. As expected, the obtained nanocomposites exhibited a clear improvement of the stress at large deformation compared to the nanocomposites filled with non grafted nanotubes. However, this is counterbalanced by a loss of the electrical properties, the nanotubes being covered by an insulating layer. The optimisation of the number and the length of the grafted chains on the nanotube surface should be a way to solve this problem.

In conclusion, mechanical and electrical properties do not necessarily depend on the same microstructural parameters. Though, it seems that they can hardly be simultaneously improved and a compromise will have to be found, depending on the expected application.

\section{Acknowledgements}

This work was performed in the frame of the European CNT-network and the GDRE No. 2756 "Science and applications of the nanotubes - NANO-E". The authors also thank Dr. 
F. Dalmas, Dr. B. Fragneaud, and Dr. M. Dehonor Gomez for their large participation to the work performed in MATEIS on nanotube nanocomposites.

\section{References}

${ }^{1}$ Thostenson E.T., Ren Z.F., Chou T.W., Composites Science and Technology, 2001, 61: 1899.

${ }^{2}$ Chazeau L., Gauthier C., Vigier G., Cavaillé J.Y., "Relationships between Microstructural Aspects and Mechanical Properties of Polymer-Based Nanocomposites", in Handbook of Organic-Inorganic Hybrid Materials and Nanocomposites. Vol. 2, American Scientific Publishers, 2003, p. 63-111.

${ }^{3}$ Nielsen L.E., Landel R.F., Mechanical properties of polymers and composites, 2nd edition, Marcel Dekker, 1994.

${ }^{4}$ Breuer O., Sundararaj U.,' Polymer Composites, 2004; 25:630-645.

${ }^{5}$ Xie X.L., Mai Y.W, Zhou X.P, Materials Science And Engineering, 2005; 49: 89-112.

${ }^{6}$ Thostenson E.T., Chou T.W., Journal of Physics D: Appl. Phys., 2002; $35: 16$.

${ }^{7}$ Sandler J., Shaffer M.S.P., Prasse T, Bauhofer W, Schulte K and Windle A, Polymer, 1999; 40: 5967.

${ }^{8}$ Qian D, Dickey E C, Andrews R and Rantell T, Applied Physics Letters, 2000; 76: 2868.

${ }^{9}$ Shaffer M.S.P, Windle A.H, Advanced Materials, 1999; 11: 937.

${ }^{10}$ Bratcher M, Gersten B, Ji H, Mays J, Materials Research Society Proceedings 2001; 706.

${ }^{11}$ Hidalgo M., Cavaillé J.Y., Guillot J., Colloid Polymer Science, 1992 ; 270 : 1208-1221.

${ }^{12}$ Chazeau L., Paillet M., Cavaillé J.Y., Journal of Polymer Science Part B : Polym. Phys. , $1999 ; 37$ : 2151-2164. 
${ }^{13}$ Favier V., Dendievel R., Canova G., Cavaillé J.Y., Gilormini P., Acta Materialia, 1997 ; 45(4) : 1557-1565.

${ }^{14}$ Dufresne A. , Paillet M. , Putaux J. L. , Canet R. , Carmona F., Delhaes P., Cui S., Journal of Materials Science, 2002; 37(18): 1573.

15 Dalmas F., Chazeau L., Gauthier C., Masenelli-Varlot K., Dendiével R., Cavaillé J.Y., Forró L., Journal of Polymer Science part B: Polym. Phys., 2005; 43: 1186-1197.

${ }^{16}$ Park C., Ouaies Z., Watson K., Crooks R., Smith J., Lowther S., Connell J., Siochi E., Harrison J., St Clair T., Chemical Physics Letters, 2002; 364: 303-308.

${ }^{17}$ Mitchell C. A., Bahr J. L., Arepalli S., Tour J.M., Krishnamoorti R., Macromolecules, 2002; 35 (23): $8825-8830$.

${ }^{18}$ Dehonor Gomez M., Masenelli-Varlot K., ., Gonzalez-Montiel A., Gauthier C., Cavaillé J.Y., Terrones M., Terrones H., Chemical Communications, 2005 ; 5349-5351.

19 Fragneaud B., Masenelli-Varlot K., Gonzalez-Montiel A., Terrones M., Cavaillé J.Y., Chemical Physics Letters, 2006 ; 419 : 567-573.

${ }^{20}$ Qu L., Lin Y., Hill D. E., Zhou B., Wang W., Sun X., Kitaygorodskiy A., Suarez M., Connell J. W., Allard L. F., Sun Y.P., Macromolecules, 2004, 37 (16) : 6055 -6060.

${ }^{21}$ Cheng X, Sastry AM, Layton BE. Journal of Engineering Materials and Technology, 2001; $123: 12-9$.

${ }^{22}$ Couteau, E.; Hernadi, K.; Seo, J. W.; Thiên-Nga, L.; Mikó, Cs.; Gaál, R.; Forró, L. Chemical Physics Letters 2003; 378: 9-17.

${ }^{23}$ Terrones M., Kamalakaran R., Seeger T., Rühle M., Chemical Communications 2000; 23: 2335.

${ }^{24}$ Bogner A., Thollet G., Basset D., Jouneau P.H., Gauthier C., Ultramicroscopy, 2005 ; 104 : 290-301. 
${ }^{25}$ Flandin L., Bréchet Y., Cavaillé J.Y., Composite Science and Technology, 2001 ; 61 : 895901.

${ }^{26}$ Dalmas F., Cavaillé J.Y., Gauthier C., Chazeau L., Dendiével R., Composite Science and Technology, 2007; 67: 829-839.

${ }^{27}$ Gass M., Koziol K., Windle A., Midgley P., Nano Letters, 2006; 6:376-379.

${ }^{28}$ Dehonor Gomez M., Masenelli-Varlot K., Gonzalez-Montiel A., Gauthier C., Cavaillé J.Y., Terrones M., Journal of Nanoscience and Nanotechnology, 2007; 7: 1-8.

${ }^{29}$ Williams M.L., Landel R.F., Ferry J.D., , Journal American Chemical Society, 1955; 77: $3701-3707$.

${ }^{30}$ Matyjaszewski K., Xia J., Chemical Reviews 2001; 101: 2921-2990.

${ }^{31}$ Fan D.Q., He J.P., Tang W., Xu J.T., Yang Y.L., European Polymer Journal 2007; 43(1): 26-34.

${ }^{32}$ Homenick C.M., Lawson G., Adronov A., Polymer Reviews 2007; 47(2): 265-290.

${ }^{33}$ Shaffer M., Koziol K., Chemical Communications, 2002; 18: 2074-2075.

${ }^{34}$ Flandin L., Bréchet Y., Canova G.R., Cavaillé J.Y., Compos Sci Technol 2001 ; 61 : 895901.

35 Fragneaud B., Masenelli-Varlot K., González-Montiel A., Terrones M., Cavaillé J.Y., Chemical Physics Letters 2007 ; 444 : 1-8.

${ }^{36}$ Boyce M.C., Parks D.M., Argon A.S., Mechanics of Materials, 1988; 7(1):15-33.

${ }^{37}$ Mangion M.B.M., Cavaille J.Y., Perez J., Philosophical Magazine A, 1992; 66(5):773-96.

${ }^{38}$ G'Sell C., Souahi A., Journal of Engineering Materials and Technology-Transactions of the ASME, 1997; 119(3):223-227.

39 Chazeau L., Cavaille J.Y., Perez J., Journal Polymer Science, Polymer Physics, 2000; 38:383-92. 